\title{
Thermal resistance of GaN HEMTs in DC/DC step-down converter measured by IR thermography
}

\author{
by B. Torzyk, B. Więcek
}

\author{
Lodz University of Technology, Institute of Electronics, 211/215 Wólczańska St. 90-924 Łódź, Poland, \\ blazejt@gmail.com, boguslaw.wiecek@p.lodz.pl
}

\begin{abstract}
This paper presents the thermographic measurements of temperature of GaN HEMTs working in the synchronous step-down DC/DC power converter. In order to estimate the power efficiency of the converter, the values of electrical parameters, such as input and output currents and voltages were measured simultaneously. Power losses in the transistors were estimated using the additional parameters of the transistors provided by the manufacturer in the application notes. At last, knowing the power loss in the transistors and temperature surplus over ambient, the thermal resistance was evaluated.
\end{abstract}

\section{Introduction}

Currently, the market in FET transistors is dominated by devices based on silicon - either Si or SiC - that are likely to feature in many applications due to their robustness, price, comparatively high efficiency and capability of handling relatively high powers [1-2]. Their prevalence is imminently coming to an end as the material is reaching the physical limits of its performance [3]. This fact accelerates the search for new and better materials or technologies that will effectively replace those based on silicon. This article focuses on the capabilities of GaN transistors used in a DC/DC step-down converter. The phenomenon behind Gallium Nitride HEMTs allows very short switching times [4-5], with the result that the size of magnetic components can be substantially reduced and power density can be increased. The most commonly used method for determining the thermal resistance [6-7] of silicon devices is based on the measurement of the voltage drop across the body diode residing in the internal structure of the component. Whereas the body diode is a significant source of switching loss in high-voltage converters, GaN transistors are majority carrier devices, and hence do not have reverse recovery-based losses associated with body diodes. The advantages of these transistors are expected to lead to the expansion of the technology into industries such as power electronics, electric car production and renewable energy generation.

\section{Synchronous step-down converter - breakdown of losses}

The synchronous step-down converter is one of the most commonly used topologies for contemporary low-voltage DC-DC regulators as shown in Figure 3. Power loss of any switch-mode converter generally falls into three groups: conduction losses, switching losses and leakage losses (normally being neglected). As the switching devices are the focus of this paper, GaN-transistor- related power loss is to be discussed in more details. Any real electric component presents resistance to current flow and dissipate power in the form of heat. Conduction losses in power for both GaN transistors in $\mathrm{DC} / \mathrm{DC}$ power converter can be ascertained by inserting their drain-source on-state resistance $\left(R_{D S(O N)}\right)-$ Equation 1.

$$
P_{C O N D}=R_{D S(O N)} \cdot I_{\text {out }}^{2}
$$

Synchronous topologies do not exhibit losses associated with diodes, usually a significant source of power dissipation, as the devices are replaced with either, as in this case, synchronous GaN HEMTs or MOS transistors. A body diode is an intrinsic part of the MOSFET design and incorporates a certain amount of power dissipation into the performance of the switch. GaN transistor, on the other hand, as a majority carrier device does not have reverse recoverybased losses and conduction losses related to body diodes.

Conduction loss in the investigated converter is the sum of the high side (HS) and the low side (LS) GaN conduction loss. This loss is independent of switching frequency, but depends strongly on the value of $R_{D S(O N)}$ which in turn is a function of temperature. The Gallium Nitride's on-resistance changes with temperature at comparable rate to the Silicon MOSFET solution.

Switching loss is associated with a finite time needed for the switching devices to turn on and off (Equation 2). During the transitions, both voltage and current are present at the HS switch, which results in power loss. The LS switch transitions can be regarded as soft (voltage across the device at the moment of a given transition can be consider zero) and thus neglected in this analysis. 


$$
P_{S W}=V_{I n} * I_{O u t} * f_{S W} * t_{S W}
$$

The remaining part of the GaN - related power loss in synchronous buck converters is associated with the charge/discharge of the devices' output capacitance (Equation 3).

$$
P_{C A P}=f_{S W} * Q_{O S S(V i n)} * V_{I n}
$$

\section{Materials and measurement setup}

A step-down converter utilizing GaN HEMTs was run at various frequencies in the range of $300 \div 1000 \mathrm{kHz}$, and the duty cycle was controlled by a signal generator. Maintaining the $30 \mathrm{~V}$ input voltage and the $15 \mathrm{~V}$ output voltage, the load changed throughout the experiment, obtaining output currents in the range $3.09 \div 5.48 \mathrm{~A}$. The basic parameters of the converter (voltage and current waveforms) were monitored and registered. The changes of temperature distribution over GaN power switches in the form of thermal images (Figure 2) were recorded in a computer by a high resolution IR cooled camera with NETD $<20 \mathrm{mK}$. Temperature measurement was recorded at the sampling frequency of $328 \mathrm{~Hz}$ during the period of 120 seconds. This gives the total of 39360 images' samples.

Based on the collected data and the analysed thermal images, the efficiency of the investigated converter as well as the thermal resistance characteristics were computed. The measurement setup is shown in Figure 1.

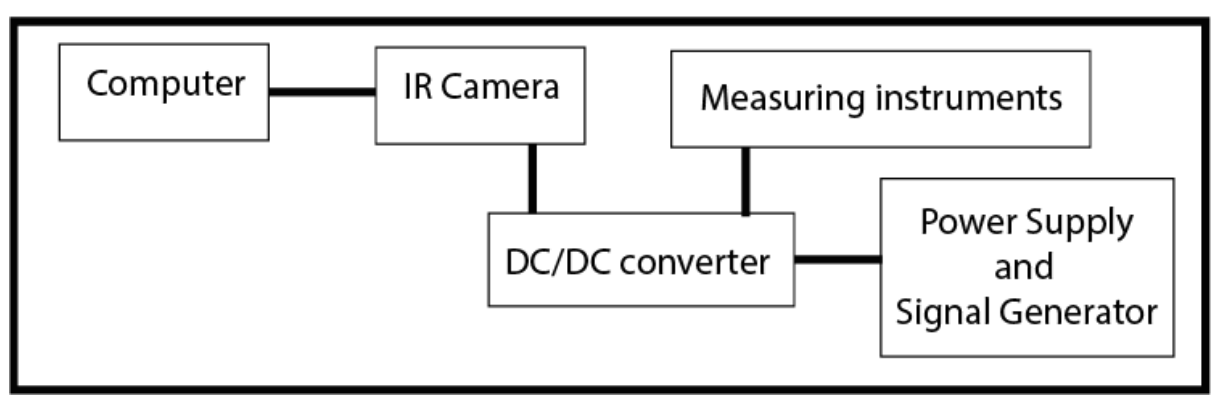

Figure 1. Block diagram of measurement setup

The example of the thermal image of both transistors is in Figure 2. Through the semi-transparent enclosure of the GaN transistor for IR radiation, the small part of semiconductor structure is visible as a higher temperature characteristic snake pattern.

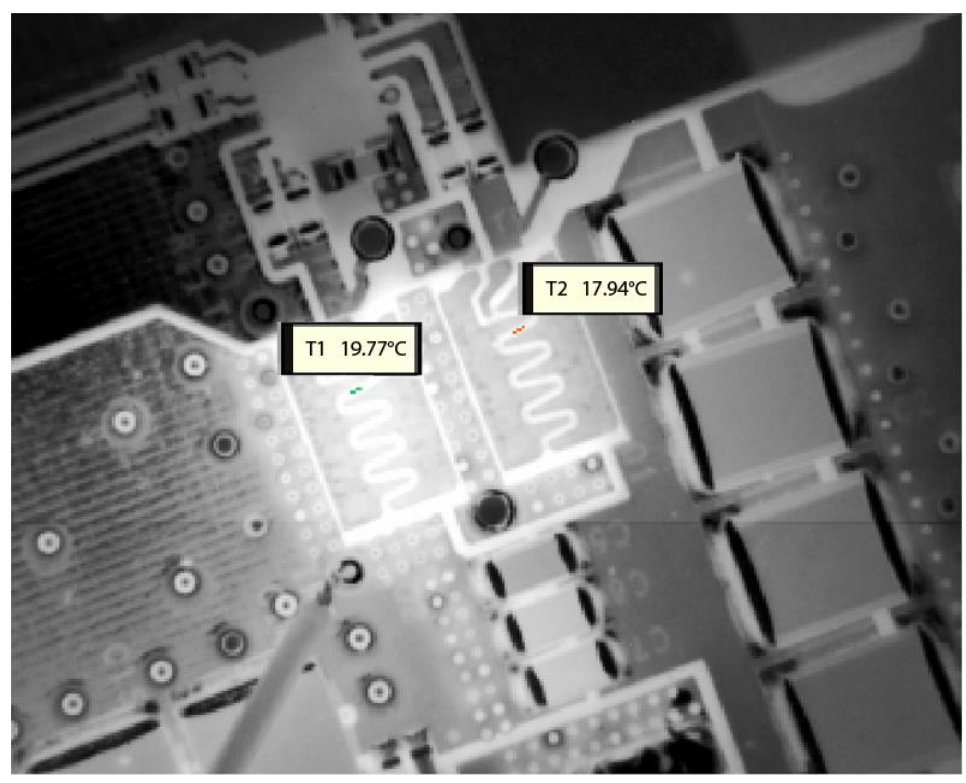

Figure 2. Thermal image of investigated GaN HEMT's T1 and T2 


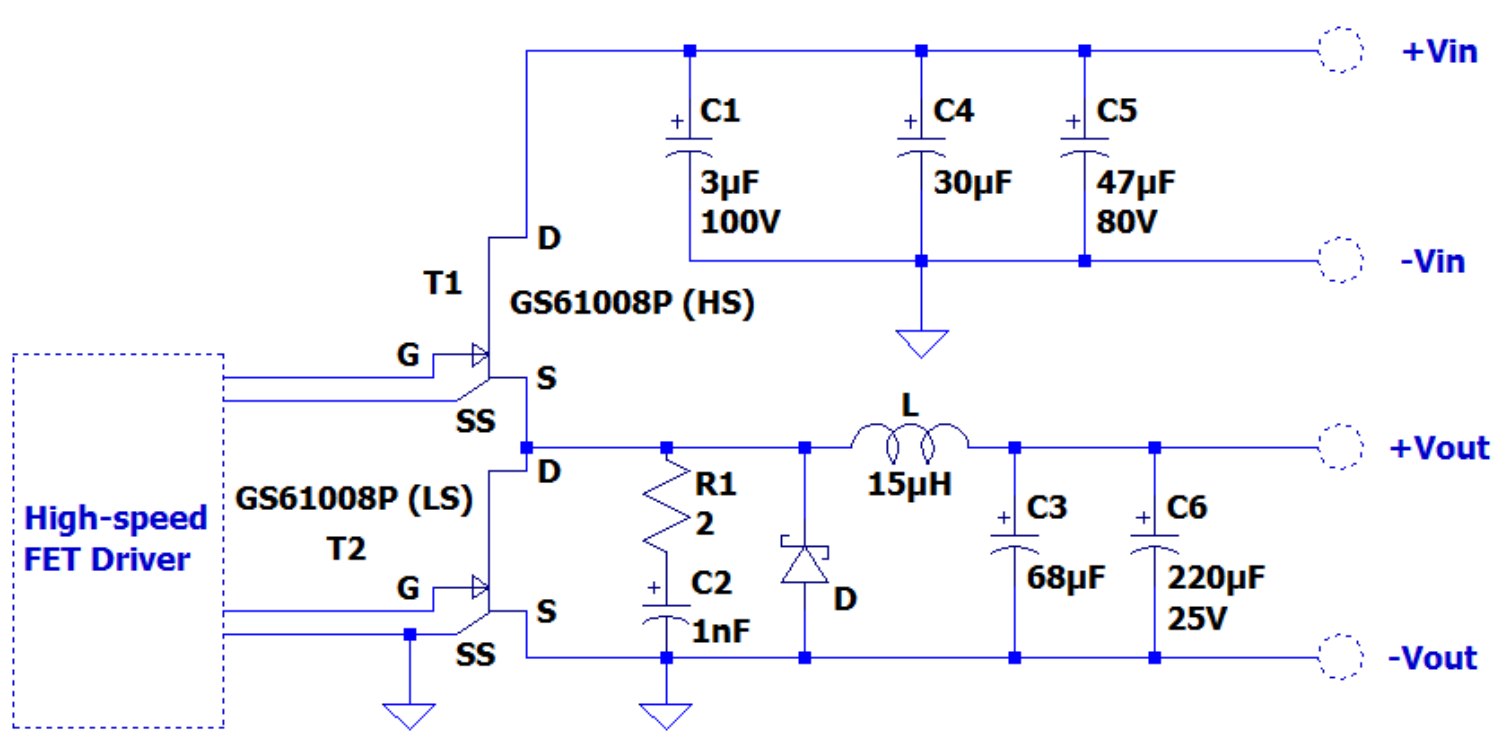

Figure 3. Reference electrical diagram of the step-down $D C / D C$ converter

\section{Results}

The recorded changes of input and output voltages and currents allowed to determine the step-down converter efficiency depending on the load and switching frequency. In the tested frequency range $300 \div 1000 \mathrm{kHz}$, DC/DC converter has the very high efficiency reaching almost $99 \%$ for 3 A load current - Figure 4.

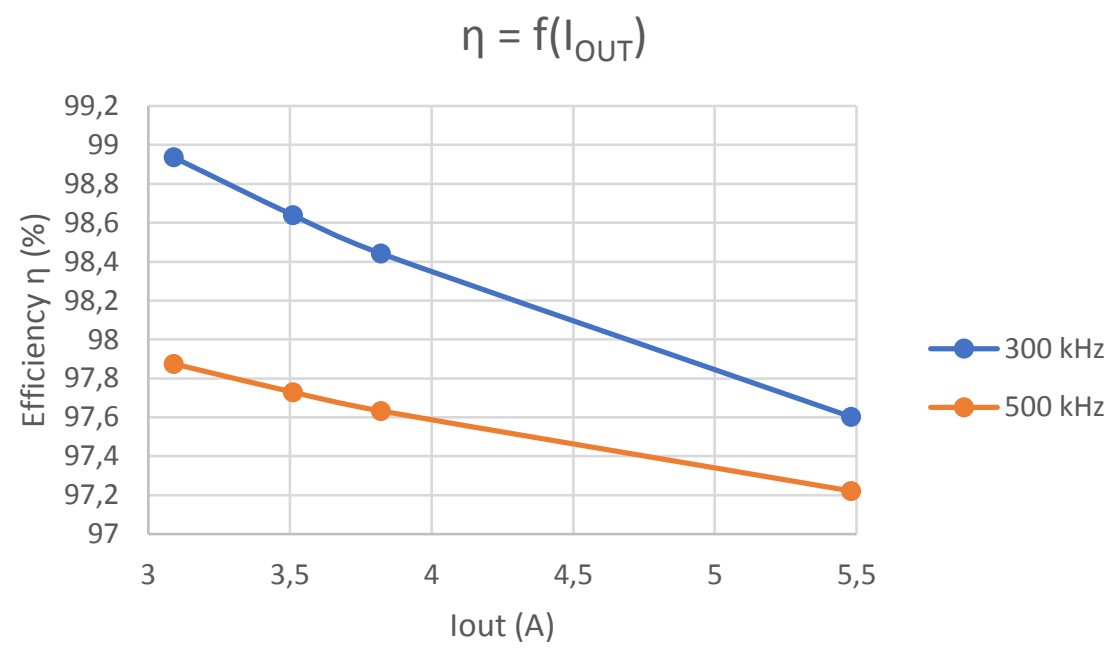

Figure 4. Changes in efficiency as a function of output current of the tested step-down DC/DC converter

Changes in load and switching frequency led to the changes in the current values flowing through the junction. As a result, the power loss $\mathrm{P}_{\mathrm{T}}$ and temperature $\Delta \mathrm{T}$ of the tested $\mathrm{GaN}$ transistors increases. The list of values presented in Table 1 allows to notice temperature differences between $\mathrm{T} 1$ and $\mathrm{T} 2$ reaching the maximum value of $2.35^{\circ} \mathrm{C}$. The difference decreases as the value of current decreases and the frequency increases. The small distance between the GaN transistors located on the PCB results in equalizing temperature values of both transistors at the similar level. Based on the observations and the above conclusions, the tested elements were treated as a single semiconductor block for the further analysis. The average temperature values $\Delta \mathrm{T}_{\mathrm{AV}}$ from both transistors are presented in Table 2 . 
Table 1. Summary of temperatures obtained on tested transistors T1 and T2

\begin{tabular}{|l|c|c|c|c|c|c|c|c|}
\hline & \multicolumn{9}{|c|}{$\Delta \mathrm{T}\left({ }^{\circ} \mathrm{C}\right)$} \\
\cline { 2 - 9 } & $3.09(\mathrm{~A})$ & \multicolumn{2}{|c|}{$3.51(\mathrm{~A})$} & \multicolumn{2}{c|}{$3.82(\mathrm{~A})$} & \multicolumn{2}{|c|}{$5.48(\mathrm{~A})$} \\
\hline $\begin{array}{c}\text { Frequency } \\
(\mathrm{kHz})\end{array}$ & $\mathrm{T} 1$ & $\mathrm{~T} 2$ & $\mathrm{~T} 1$ & $\mathrm{~T} 2$ & $\mathrm{~T} 1$ & $\mathrm{~T} 2$ & $\mathrm{~T} 1$ & $\mathrm{~T} 2$ \\
\hline 300 & 15.82 & 14.61 & 15.29 & 14.36 & 15.60 & 14.38 & $\mathbf{1 7 . 3 9}$ & $\mathbf{1 5 . 0 4}$ \\
\hline 500 & 19.51 & 17.41 & 19.77 & 17.94 & 20.05 & 17.95 & 25.08 & 24.70 \\
\hline 750 & 22.17 & 20.49 & 22.36 & 20.24 & 25.61 & 23.49 & 25.18 & 25.29 \\
\hline 1000 & 25.49 & 25.93 & 25.56 & 25.08 & 25.58 & 26.15 & 25.54 & 25.68 \\
\hline
\end{tabular}

Table 2. The average temperature of the tested GaN transistors

\begin{tabular}{|l|l|l|l|l|}
\hline \multirow{2}{*}{$\begin{array}{l}\text { Frequency } \\
(\mathrm{kHz})\end{array}$} & \multicolumn{4}{|c|}{$\Delta \mathrm{T}_{\mathrm{AV}}\left({ }^{\circ} \mathrm{C}\right)$} \\
\cline { 2 - 5 } & $3.09(\mathrm{~A})$ & $3.51(\mathrm{~A})$ & $3.82(\mathrm{~A})$ & $5.48(\mathrm{~A})$ \\
\hline 300 & 15.22 & 14.83 & 14.99 & 16.21 \\
\hline 500 & 18.46 & 18.86 & 19.00 & 24.89 \\
\hline 750 & 21.33 & 21.30 & 24.55 & 25.24 \\
\hline 1000 & 25.71 & 25.33 & 25.86 & 25.62 \\
\hline
\end{tabular}

Applying the equations (1-3) allows determining the power loss of operating transistors $\mathrm{P}_{\mathrm{T}}$. For calculation of the Psw of the GaN transistor, tsw = 11.7 ns was used, which was given by the producer [8]. The information applies to a $650 \mathrm{~V}$ transistor, but it is the same product family. Based on the obtained values (Table 3), $\mathrm{P}_{\mathrm{T}}$ increases with the increasing switching frequency and current value.

Table 3. Power loss in the a step-down DC/DC converter with GaN HEMT transistors

\begin{tabular}{|l|l|l|l|l|}
\hline \multirow{2}{*}{ Frequency $(\mathrm{kHz})$} & \multicolumn{4}{|c|}{$\mathrm{P}_{\mathrm{T}}(\mathrm{W})$} \\
\cline { 2 - 5 } & $3.09(\mathrm{~A})$ & $3.51(\mathrm{~A})$ & $3.82(\mathrm{~A})$ & $5.48(\mathrm{~A})$ \\
\hline 300 & 1.23 & 1.37 & 1.48 & 2.19 \\
\hline 500 & 1.89 & 2.11 & 2.25 & 3.20 \\
\hline 750 & 2.74 & 3.01 & 3.24 & 4.43 \\
\hline 1000 & 3.58 & 3.93 & 4.22 & 5.69 \\
\hline
\end{tabular}

$$
P_{T}=f(\text { lout })
$$

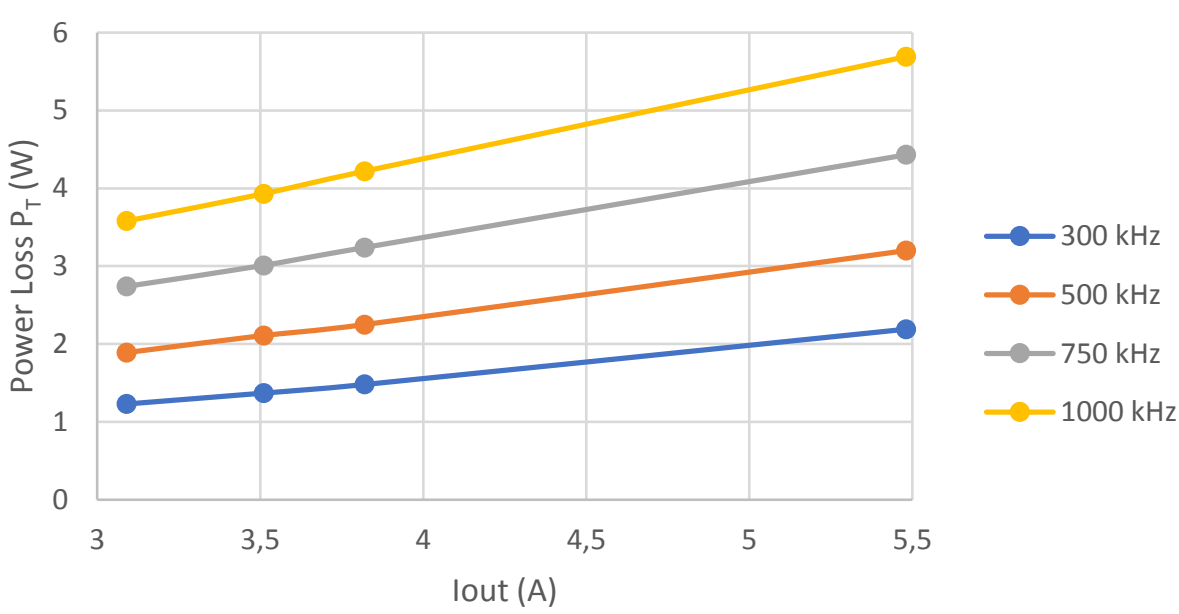

Figure 5. Power loss on transistors relative to the output current

Having the values of $\Delta \mathrm{T}_{\mathrm{AV}}$ and $\mathrm{P}_{\mathrm{T}}$, it's possible to determine the next parameter which is the thermal resistance $\mathrm{R}_{\mathrm{th}}$, according Equation 4.

$$
R_{t h}=\frac{\Delta T_{A V}}{P_{T}}
$$

The determined thermal resistance values, which are shown in Table 4, cover the range $4.50 \div 12.36{ }^{\circ} \mathrm{C} / \mathrm{W}$. $R_{\text {th }}$ changes are highly correlated with the increase of frequency and the increase of the current value. The graphical representation of the changes of the thermal resistance is shown in Figure 6. 
Table 4. Average thermal resistance of tested transistors

\begin{tabular}{|l|l|l|l|l|}
\hline \multirow{2}{*}{$\begin{array}{c}\text { Frequency } \\
(\mathrm{kHz})\end{array}$} & \multicolumn{4}{|c|}{ Thermal resistance $\mathrm{R}_{\text {th }}\left({ }^{\circ} \mathrm{C} / \mathrm{W}\right)$} \\
\cline { 2 - 5 } & $3.09(\mathrm{~A})$ & $3.51(\mathrm{~A})$ & $3.82(\mathrm{~A})$ & $5.48(\mathrm{~A})$ \\
\hline 300 & 12.36 & 10.79 & 10.14 & 7,41 \\
\hline 500 & 9.77 & 8.90 & 8.44 & 7.77 \\
\hline 750 & 7.79 & 7.07 & 7.57 & 5.70 \\
\hline 1000 & 7.18 & 6.45 & 6.13 & 4.50 \\
\hline
\end{tabular}

$$
R_{\text {th }}=f(\text { Freq) }
$$

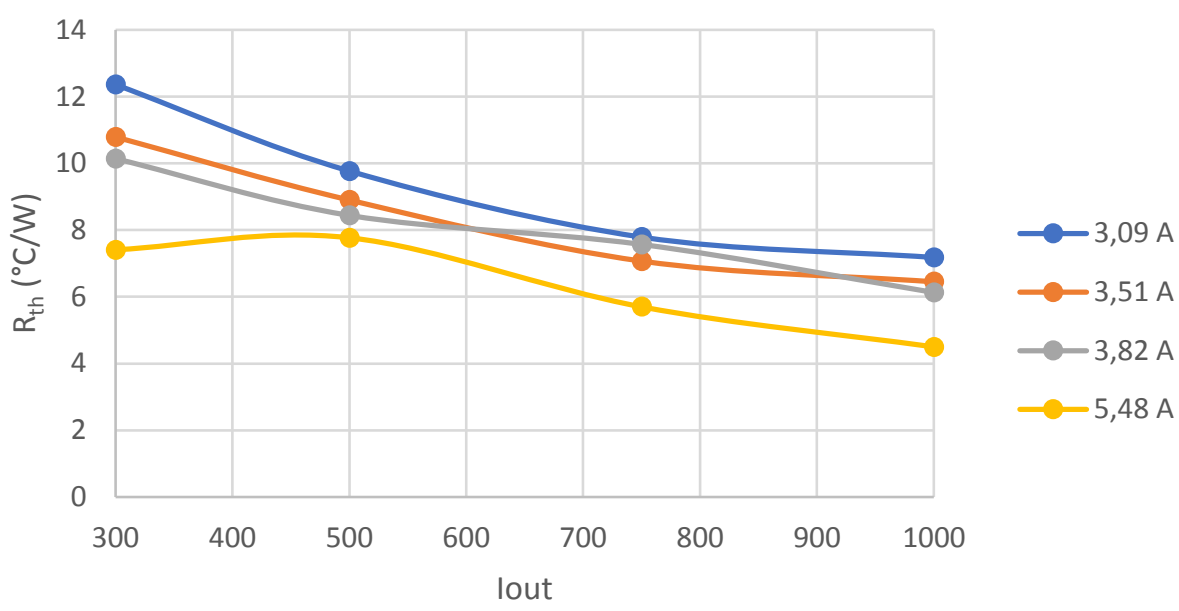

Figure 6. Changes of thermal resistance depending on the current value and switching frequency for transistors in $D C / D C$ step-down power converter

\section{Conclusions}

The study allowed to document changes in electrical and thermal parameters of the step-down DC/DC converter. The simplified analysis applied to the GaN transistors exhibited the differences in temperature changes resulting from the different switching frequency and load. The high efficiency of the converter reaching almost $99 \%$ is confirmed by the small power losses - Table 3. As a result, the temperature rise of the tested GS61008P transistors relative to the ambient temperature is relatively small as shown in Table 1 . The maximum temperature value of a single transistor reaches $25^{\circ} \mathrm{C}$ above ambient.

In addition, the presented engineering method of monitoring and recording electrical parameters of DC/DC power converter together with temperature measurement using an IR camera allows to estimate the thermal resistance of the tested elements. 


\section{REFERENCES}

[1] J. Ortiz Gonzalez, R. Wu, S.N. Agbo, O. Alatise, "Robustness and reliability review of Si and SiC FET devices for more electric-aircraft applications", Microelectronics Reliability, pp. 100-101, 2019.

[2] Ch. Onambele, A. Mpanda, M. Elsied, F. Giacchetti, "Highly Efficient Driver System based on SiC MOSFETs for High Power Electric Transportation", IEEE Power Electronics and Power Engineering, pp. 229-234, 2017.

[3] R. W. Keyes, "Physical limits of silicon transistors and circuits", Reports on Progress in Physics, vol.68, pp. 2701-2746, 2005.

[4] T. Tanaka, T. Ueda, and D. Ueda, "Highly efficient GaN power transistors and integrated circuits with high breakdown voltages," in Proc. IEEE ICSICT, Shanghai, China, pp. 1315-1318, 2010.

[5] S. Hoshi, M. Itoh, T. Marui, H. Okita, Y. Morino, I. Tamai, F. Toda, S. Seki, and T. Egawa, "12.88W/mm GaN high electron mobility transistor on silicon substrate for high voltage operation," Appl. Phys. Exp., vol. 2, no. 6, p. $061001,2009$.

[6] P. Kawka, G. De Mey, B. Vermeersch, "Thermal characterization of electronic packages using the Nyquist plot of the thermal impedance", IEEE Transaction on Components and Packaging Technologies, vol.30, pp. 660$665,2007$.

[7] B. Vermeersch, G. De Mey, "Thermal impedance plots of micro scaled devices", Microelectronics Reliability, vol.46, pp.174-177, 2006.

[8] GaN Systems, GN001 Application Brief: How to drive GaN Enhancement mode HEMT, 2016, available at https://www.mouser.cn/pdfDocs/343654 GaNSystems GN001 How To drive GaN EHEMT Rev 20160426 .pdf access on 03.07.2020. 